\title{
Features of residency training and psychological distress among residents in a Nigerian teaching hospital
}

\author{
O Esan, ${ }^{1}$ MBBS, MSc, FWACP; A Adeoye, ${ }^{2} \mathrm{MB}$ ChB, FWACP; P Onakoya, ${ }^{3}$ FWACP, FMCORL; O Opeodu, ${ }^{4} \mathrm{~B}, \mathrm{ChD}, \mathrm{FWACP}$ \\ K Owonikoko, ${ }^{5}$ MBBS, FMCOG; D Olulana, ${ }^{6}$ MBBS, FWACS; M Bello, ${ }^{7}$ MBBS, FWACS; A Adeyemo, ${ }^{8}$ MBBS, FWACS; \\ L Onigbogi, ${ }^{9}$ MBBS, FWACP; O Idowu, ${ }^{10}$ MBBS, FWACS; T Akute, ${ }^{11}$ MBBS \\ ${ }^{1}$ Department of Psychiatry, University of Ibadan, Nigeria \\ ${ }^{2}$ Department of Pathology, University of Ibadan, Nigeria \\ ${ }^{3}$ Department of Otorhinolaryngology, University of Ibadan, Nigeria \\ ${ }^{4}$ Department of Peridontal and Community Dentistry, University of Ibadan, Nigeria \\ ${ }^{5}$ Department of Obstretics and Gynaecology, Ladoke Akintola University of Technology, Ogbomoso, Nigeria \\ ${ }^{6}$ Department of Surgery, University of Ibadan, Nigeria \\ ${ }^{7}$ Department of Radiology, University College Hospital, Ibadan, Nigeria \\ ${ }^{8}$ Institute of Child Health, University of Ibadan, Nigeria \\ ${ }^{9}$ Department of Community Medicine, University College Hospital, Ibadan, Nigeria \\ ${ }^{10}$ Reddington Multispecialist Hospital, Victoria Island, Lagos, Nigeria \\ ${ }^{11}$ Department of Obstretics and Gynaecology, University College Hospital, Ibadan, Nigeria
}

Corresponding author: O Esan (oluyomie@yahoo.com)

\begin{abstract}
Background. Resident doctors at University College Hospital (UCH), Ibadan, Nigeria, made a series of complaints about inadequate consultant supervision, lack of structure in the training programme and excessive workload. These complaints led to an evaluation of residency training.

Objective. To investigate perceptions of the residency training programme and levels of psychological distress among residents.

Methods. All 250 resident doctors at UCH were invited to complete questionnaires about their residency training and general health as part of a cross-sectional study. Data were analysed using SPSS 16.

Results. A total of 128 residents (51.2\%) responded to the questionnaire. Of the respondents, $72 \%$ rated their consultant supervision as good and $82.6 \%$ rated support from nurses as good; $61.8 \%$ had $<5$ hours of formal educational activities and $65.1 \%$ had $<5$ hours of research or private study per week. There was evidence of psychological distress in $48.4 \%$ of the respondents, and there was a significant association between psychological distress and the intensity of work $(p<0.01)$.

Conclusion. The residency training programme at UCH appears to prioritise service provision over research and education activities. Residents who report high workloads also have high levels of psychological distress. Tackling these issues could improve overall satisfaction with residency training and reduce complaints.
\end{abstract}

S Afr J Psych 2014;20(2):46-50. DOI:10.7196/SAJP.426

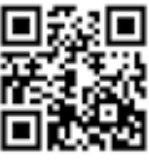

The quality of healthcare and medical research in a country depends in part on the quality of postgraduate residency training. In Nigeria, reports of medical malpractice and negligence are increasing, and this trend has been attributed by some to the widening gap between postgraduate medical education and ideal standards of medical practice. The issues of who should train postgraduate medical doctors, and whether training should be hospital or university based, are contentious. ${ }^{[1]}$ Most residency training, both inside and outside Nigeria, is hospital based and professionally regulated, as opposed to university based with regulation by educators. However, it has been shown that education and training have suffered in favour of service provision in hospitals that train residents. ${ }^{[2-4]}$ Common criticisms of resident training programmes include being too hospital focused, with too much emphasis on provision of services with little or no educational value. Very little attention is given to each resident's needs, and much is left for residents to find out for themselves. Increases in the numbers of specialties and subspecialties have created fragmentation in and between departments and reduced cohesion of residency training programmes. Compared with the previous century, arriving at a diagnosis or ruling out a differential diagnosis currently involves more procedures and investigations. Hospital-based training means that most residents are trained with sicker patients. These two factors increase the workload for residents and mean that service provision is often prioritised over educational goals. ${ }^{[1]}$

A national survey of residents completing their residency in eight major specialties in the USA found that $>10 \%$ of residents in each specialty felt unprepared to undertake at least one task 
relevant to their discipline. Specific tasks for which respondents felt least prepared included: caring for patients with HIV/AIDS (family practice) or nursing home patients (internal medicine); performance of spinal surgery (orthopaedic surgery) or abdominal aortic aneurysm repair (general surgery); and management of chronic pain (anaesthesiology). A study by Grant et al. ${ }^{[5]}$ also in the USA, showed that residency training programmes do not prepare the residents for the cases they see in practice.

At the University College Hospital (UCH), Ibadan, Nigeria, anecdotal reports of complaints from residents mirror those documented in the literature. These complaints range from a shortage of human resources to heavy workloads that hinder learning, inadequate consultant supervision, lack of structure in residency training programmes and inadequate remuneration. In contrast, anecdotal reports from some consultants (trainers) describe residents as 'lazy' and 'unteachable. Since no previous study has evaluated residency training in Nigeria, we sought to design a study to document the problems faced by residents at $\mathrm{UCH}$.

\section{Objectives}

Our objective was to assess residency training in an institution accredited for postgraduate medical training in Nigeria, to assess psychological distress, and to look for any association between residency training and psychological distress.

\section{Methods \\ Subjects}

The study population for this cross-sectional study comprised all 250 resident doctors in training at $\mathrm{UCH}$ in September 2006. $\mathrm{UCH}$ is an 812-bed teaching hospital located in Ibadan, SouthWestern Nigeria. The estimated population of South-Western Nigeria is about 28 million. ${ }^{[6]}$ The hospital receives referrals from health facilities in the South-Western geopolitical zone and frequently from other geopolitical zones of the country. This survey was conducted under the auspices of the UCH Association of Resident Doctors (ARD), which comprises all resident doctors in the hospital. All specialties involved in training residents had representatives in the Residency Training Committee of the association. These representatives were trained on the study questionnaires to ensure inter-rater reliability and enhance the validity and quality of captured responses. They were then asked to distribute the questionnaires to the target groups.

Questionnaires were distributed to all 250 residents at $\mathrm{UCH}$. Completed questionnaires were returned to departmental representatives, and subsequently to the chairman of the Residency Training Committee of the association for compilation, data entry and analysis.

\section{Questionnaires}

The questionnaire was divided into two parts: (i) a series of 29 questions assessing the residency training; and (ii) the widely used 12-part General Health Questionnaire (GHQ-12). ${ }^{[7,8]}$ Residency training questions included items such as 'Did you sit down with your consultant to discuss your educational objectives at the beginning of this posting?' and 'Have you used a logbook in this posting?' Survey questions were modified iteratively by the members of the Residency
Table 1. Distribution of respondents by specialty

\begin{tabular}{ll}
\hline Specialty & $\boldsymbol{n}(\%)$ \\
\hline Psychiatry & $9(7.0)$ \\
Pathology & $8(6.3)$ \\
Obstetrics and gynaecology & $24(18.8)$ \\
Internal medicine & $12(9.4)$ \\
Anaesthesia & $9(7.0)$ \\
Ophthalmology & $3(2.3)$ \\
Radiology/radiotherapy & $10(7.8)$ \\
Paediatrics & $4(3.1)$ \\
Surgery & $21(16.4)$ \\
General practice & $7(5.5)$ \\
Community medicine & $14(10.9)$ \\
Others & $6(4.7)$ \\
Total & $127^{*}(99.2)$ \\
$*$ One respondent did not complete this field in the questionnaire. &
\end{tabular}

Table 2. Assessment of training

\begin{tabular}{|c|c|c|}
\hline \multirow[b]{2}{*}{ Question } & \multicolumn{2}{|c|}{ Response $^{\star}(\%)$} \\
\hline & Yes & No \\
\hline $\begin{array}{l}\text { Did you sit down with your consultant to discuss } \\
\text { your educational objectives at the beginning of this } \\
\text { posting? }\end{array}$ & 28.1 & 64.8 \\
\hline Have you used a logbook in this post? & 37.5 & 59.4 \\
\hline $\begin{array}{l}\text { Did you receive an induction to this hospital when } \\
\text { you started? }\end{array}$ & 36.7 & 57.0 \\
\hline $\begin{array}{l}\text { Did you also receive an induction to your department } \\
\text { (e.g. routines, key staff and protocols) }\end{array}$ & 56.3 & 43.0 \\
\hline $\begin{array}{l}\text { Have you sat down with your consultant to discuss } \\
\text { your progress? }\end{array}$ & 40.6 & 54.7 \\
\hline $\begin{array}{l}\text { Have you had an end-of-year assessment in this or } \\
\text { your previous post? }\end{array}$ & 19.5 & 75.8 \\
\hline Is your pay commensurate with your work? & 9.4 & 77.3 \\
\hline $\begin{array}{l}\text { Do you feel ready to take up a consultant post in the } \\
\text { next one year? }{ }^{\dagger}\end{array}$ & 60.0 & 40.0 \\
\hline
\end{tabular}

Training Committee of the ARD to ensure relevance of content, unambiguous wording and appropriateness to training.

The GHQ questionnaire has been used widely to assess overall psychological wellbeing and to detect non-psychotic psychiatric problems, and has good validity, reliability and internal consistency. ${ }^{[9,10]}$ Questions relating to anxiety, depression, social dysfunction and loss of self-esteem were included. A simple scoring method was applied, with 0 representing the ratings 'not at all' and 'about as much as usual', and 1 representing 'more than usual' and 'strong feeling. The lowest total score was 0 while the highest total score was 12 . Psychological morbidity was calculated using the total score first, and then respondents were divided into cases and non-cases using a cut-off point total score of 2 . 
Table 3. Rating of supervision, support and hands-on experience

\begin{tabular}{lll}
\hline Question & Good (\%) & Poor (\%) \\
\hline How would you rate the consultant supervision in this post? & 78.2 & 21.8 \\
How would you rate the support you get from nurses (midwives) in the post? & 82.9 & 17.1 \\
How would you rate the 'hands-on' experience you are acquiring in this post? & 92.3 & 7.7
\end{tabular}

Table 4. Hours of research and educational activities

\begin{tabular}{llll}
\hline Question & None (\%) & $\mathbf{1 ~ - 5 ~ h o u r s ~ ( \% ) ~}$ & $>\mathbf{5}$ hours (\%) \\
\hline $\begin{array}{l}\text { How many hours of formal (organised and } \\
\text { timetabled) educational activities do you attend } \\
\text { on average each week? }\end{array}$ & 2.3 & 59.5 & \\
$\begin{array}{l}\text { How many hours of research or private study } \\
\text { time do you get on average each week? }\end{array}$ & 10.9 & 54.2 & 34.9
\end{tabular}

\section{Analysis}

SPSS version 16 was used for the statistical analyses. Proportions and percentages were used to summarise qualitative data. The association between psychological distress and subject characteristics such as gender and rating of consultant supervision were explored by means of $\chi^{2}$ tests.

\section{Results}

There were 128 respondents, 94 (73.4\%) male and 34 (26.6\%) female. This study population represented $51 \%$ of the residents in the hospital. All specialties of the hospital were represented (Table 1). The highest number of respondents $(n=24)$ came from the obstetrics and gynaecology department. Only $28.1 \%$ of the respondents had had interaction with their consultants to discuss their educational objectives. Less than $40 \%$ had used a logbook in their current posting. Only $36.7 \%$ had an induction into the hospital at the beginning of their residency training; however, $56.3 \%$ had an induction into their department at the beginning of their residency programme. Less than $20 \%$ had an end-of-year assessment in their current or previous postings. Less than $10 \%$ felt that their pay was commensurate with the volume of work they did. The majority $(60.0 \%)$ of those who expected to finish the residency programme within 12 months of conducting the study felt ready to take up a consultant appointment (Table 2).

Most (78.2\%) of the respondents rated the supervision they got from their consultants, hands-on experience (92.3\%) and support from nurses (82.9\%) as good (Table 3). Among the respondents, $61.8 \%$ had $<5$ hours of formal educational activities per week, and $65.1 \%$ had $<5$ hours of research or private study per week (Table 4).

With respect to intensity of work, 55.4\% reported their workload to be excessive or heavy, while $41.6 \%$ felt that it was light or satisfactory. Most respondents (81.3\%) had never taken their full complement of 28 working days' annual leave. Of those who gave reasons for not taking all their leave, $56 \%$ stated that they could not meet their call duty allowance (320 hours) if they did so, and $32 \%$ attributed untaken leave to inadequate staffing and work overload.

\section{Psychological distress}

Using a cut-off point of 2, psychological distress was present in $48.4 \%$ of the subjects. Recorded GHQ-12 scores ranged between 0 and 11 , with a median of 1 . A significantly higher proportion of respondents who did not interact with their consultants to discuss the educational objectives of their current posting had psychological distress compared with respondents who discussed such objectives with their consultants (Table 5). Also, a significantly higher proportion of residents who rated the intensity of work in their current posting as heavy or excessive had psychological distress compared with those who rated the intensity of work as light or moderate.

\section{Discussion}

The results of this cross-sectional assessment show that residents have heavy workloads and little time devoted to formal educational activities; however, supervision by consultants and support from nurses seem to be good in the majority of cases. Of the respondents,
$>50 \%$ described the intensity of the work they did as excessive or heavy, and most residents had never taken their full complement of leave as a result of work pressures. Heavy workload has been shown to influence residents' education negatively, impair educational experience and compromise clinical care. ${ }^{[1]}$

Although very few of the respondents $(<30 \%)$ had discussed their educational objectives with their consultants, and $<20 \%$ had done an end-of-year assessment in their current or previous postings, $>75 \%$ nevertheless described the consultant supervision as good. This paradoxical finding may be explained by the fact that 'supervision' includes time spent monitoring service delivery as well as educational attainment, an interpretation that is backed up by the fact that $92.5 \%$ of residents rated handson experience and skills acquisition as good.

Extensive practical experience is essential for residents in the surgical specialties such as general surgery, and obstetrics and gynaecology, and can be regarded as a positive finding about the training programme. Unfortunately, however, this experience seems to be at the expense of teaching and researchrelated activities necessary to update residents on current scientific trends.

Another area of perceived deficiency was time spent in private study. Formal educational activities such as morning clinical meetings, journal clubs, and morbidity and mortality meetings comprised $<1$ hour per week for $>70 \%$ of residents. Among those who responded to this question, $72 \%$ reported that no such activities were provided, and $28 \%$ reported that they were too busy to attend. However, $>30 \%$ had at least $>5$ hours of private study and research per week, suggesting that individual motivation is a likely contributing factor.

For residents who did not do their undergraduate training at $\mathrm{UCH}$, induction sessions were a useful tool for understanding the training programme and the hospital. Less than $40 \%$ of residents said they had been through such a session for the hospital in general, although $>50 \%$ of the residents had department-specific inductions. Despite the perceived deficiency, $60 \%$ of the respondents who were within a year of the end of their training felt ready to take up a consultancy position. This outcome is similar to results from a national survey of residents completing their residency in eight major 


\section{var 12

Table 5. Bivariate analysis of factors associated with psychological distress

\begin{tabular}{|c|c|c|c|c|}
\hline \multirow[b]{2}{*}{ Characteristics } & \multicolumn{2}{|c|}{ Psychological distress } & \multirow[b]{2}{*}{$\chi^{2}$} & \multirow[b]{2}{*}{$p$-value } \\
\hline & No, $n(\%)$ & Yes, $n(\%)$ & & \\
\hline \multicolumn{5}{|l|}{ Gender } \\
\hline Male & $45(47.9)$ & $49(52.1)$ & 1.93 & 0.16 \\
\hline Female & $21(61.8)$ & $13(38.2)$ & & \\
\hline \multicolumn{5}{|c|}{ Is your pay commensurate with your work? } \\
\hline Yes & $7(58.3)$ & $5(41.7)$ & 0.71 & 0.40 \\
\hline No & $45(45.5)$ & $54(54.5)$ & & \\
\hline \multicolumn{5}{|c|}{$\begin{array}{l}\text { Did you sit down with your consultant to discuss your educational objectives at the beginning } \\
\text { of this posting? }\end{array}$} \\
\hline Yes & $24(66.7)$ & $12(33.3)$ & 4.90 & 0.03 \\
\hline No & $37(44.6)$ & $46(55.4)$ & & \\
\hline \multicolumn{5}{|c|}{ Did you receive an induction to this hospital when you started? } \\
\hline Yes & $38(52.8)$ & $24(47.2)$ & 0.17 & 0.48 \\
\hline No & $27(49.1)$ & $28(50.9)$ & & \\
\hline \multicolumn{5}{|c|}{ How would you rate the consultant supervision in this post? } \\
\hline Poor & $35(46.7)$ & $40(53.3)$ & 1.49 & 0.22 \\
\hline Good & $30(57.7)$ & $22(42.3)$ & & \\
\hline \multicolumn{5}{|c|}{ How would you rate the support you get from nurses? } \\
\hline Poor & $34(49.3)$ & $35(50.7)$ & 0.14 & 0.71 \\
\hline Good & $30(52.6)$ & $27(47.4)$ & & \\
\hline \multicolumn{5}{|c|}{ How many hours of formal educational activities do you attend on average? } \\
\hline$<4$ & $27(48.2)$ & $29(51.8)$ & 0.45 & 0.51 \\
\hline$\geq 4$ & $39(54.2)$ & $33(45.8)$ & & \\
\hline \multicolumn{5}{|c|}{ How would you rate the hands-on experience you have received? } \\
\hline Poor & $30(50.0)$ & $30(50.0)$ & 0.03 & 0.86 \\
\hline Good & $31(51.7)$ & $29(48.3)$ & & \\
\hline \multicolumn{5}{|c|}{ How would you rate the intensity of work in this post? } \\
\hline Light/moderate & $38(70.4)$ & $16(29.6)$ & 13.98 & $<0.01$ \\
\hline Heavy/excessive & $26(36.6)$ & $45(63.4)$ & & \\
\hline
\end{tabular}

specialties in the USA, where residents in their last year of training at academic health centres rated their clinical preparedness as high despite the fact that $>10 \%$ of them felt incapable of performing one or more tasks in the their respective specialties. ${ }^{[11]}$

Nearly half $(48 \%)$ of the respondents met the criteria for current psychological distress. There was a positive correlation between distress and reported intensity of work, and also with the absence of discussions of educational objectives with supervising consultants. The high prevalence of current psychological distress is similar to that reported by a study in Europe done among university hospital physicians. In this study, $42.7 \%$ of the participants showed current psychological ill health. ${ }^{[12]}$ Similarly, a systematic review of depression, anxiety and other indicators of psychological distress among US and Canadian medical students showed a high prevalence of depression and anxiety, with levels of overall psychological distress consistently higher than in the general population. The authors concluded that medical school is a time of significant psychological distress for physicians in training. ${ }^{[13]}$ It is therefore logical that residency training, which is even more rigorous, would also induce stress, with associated negative implications for patient care.

In 2003, the Accreditation Council for Graduate Medical Education in the USA issued a directive limiting resident doctors' working hours. Following this recommendation, a study examining the impact of these restrictions on residency training programmes from the residents' perspectives showed that most residents (67\%) agreed that their mental health had improved. ${ }^{[14]}$ This finding corroborates the findings of our study of the association of perceived excessive work with psychological distress.

Despite the perceived deficiencies in the current residency training programme at $\mathrm{UCH}$ as reported by residents, the study produced some positive findings, including $90 \%$ of respondents rating handson experience as good, and $>75 \%$ rating consultant supervision as good. However, education and research activities seem to have a lower priority than service provision practice. 
We recommend that, to redress this imbalance, residents should see a limited number of patients at any one time and should be assigned fewer non-educational tasks during training. Attempts should be made to ease emotional stresses and financial pressures and to improve discussion of learning objectives. There should also be an annual assessment of progress.

Study limitation. The low response rate from residents is a limitation of this study.

\section{Conclusion}

In conclusion, the current residency training programme at $\mathrm{UCH}$ seems to favour service provision over research and education activities, and this imbalance affects residents' perceptions of the programme. There is also evidence to suggest a high prevalence of psychological distress among resident doctors that is related to their self-reported workloads.

\section{References}

1. Cohen JJ. Honoring the 'E' in GME. Presentation to the 3rd Annual Meeting of the American Association of Colleges of Osteopathic Medicine, Bethesda, MD, USA, 23 June 2005.

2. Ludmerer KM, Johns MM. Reforming graduate medical education. JAMA 2005;294(9):1083 1087. [http://dx.doi.org/10.1001/jama.294.9.1083]
3. Lesky LG. The ever-widening training-practice gap. Acad Med 2007;82(3):219-221. [http:// dx.doi.org/10.1097/ACM.0b013e3180305b6f]

4. Tsai TC, Harasym PH. Challenges of pediatric residency training in Taiwan. Acta Paediatr Taiwan 2006;47(1):3-6.

5. Grant E, Macnab A, Wambera K. The effectiveness of pediatric residency education in preparing graduates to manage neurological and neurobehavioral issues in practice. Acad Med 2007;82(3):304-309. [http://dx.doi.org/10.1097/ACM.0b013e31803080c8]

6. National Population Commission Nigeria. National Census, 2006. Abuja: National Population Commission, 2006.

7. Goldberg D, Williams P. A user's guide to the General Health Questionnaire. Windsor: NFERNelson, 1988.

8. Goldberg D. The detection of psychiatric illness by questionnaire: A technique for the identification and assessment of non-psychotic psychiatric illness. Oxford: Oxford University Press, 1972.

9. Quek KF, Low WY, Razack AH, Loh CS. Reliability and validity of the General Health Questionnaire (GHQ-12) among urological patients: A Malaysian study. Psychiatry Clin Neurosci 2001;55(5):509-513. [http://dx.doi.org/10.1046/j.1440-1819.2001.00897.x]

10. Sanchez-Lopez Mdel P, Dresch V. The 12-Item General Health Questionnaire (GHQ-12): Reliability, external validity and factor structure in the Spanish population. Psicothema 2008;20(4):839-843

11. Blumenthal D, Gokhale M, Campbell EG, Weissman JS. Preparedness for clinical practice: Reports of graduating residents at academic health centers. JAMA 2001;286(9):10271034.

12. Russ TC, Stamatakis E, Hamer M, Starr JM, Kivimaki M, Batty GD. Association between psychological distress and mortality: Individual participant pooled analysis of 10 prospective cohort studies. BMJ 2012;345:e4933. [http://dx.doi.org/10.1136/bmj.e4933]

13. Dyrbye LN, Thomas MR, Shanafelt TD. Systematic review of depression, anxiety, and other indicators of psychological distress among US and Canadian medical students. Acad Med 2006;81(4):354-373.

14. Brunworth JD, Sindwani R. Impact of duty hour restrictions on otolaryngology training: divergent resident and faculty perspectives. Laryngoscope 2006;116(7):1127-1130. [dx.doi. org/10.1097/01.mlg.0000224348.44616.fb] 